CARDIOVASCULAR MEDICINE

\title{
Myocardial ischaemia and the inflammatory response: release of heat shock protein 70 after myocardial infarction
}

\author{
B Dybdahl, S A Slørdahl, A Waage, P Kierulf, T Espevik, A Sundan
}

Heart 2005;91:299-304. doi: 10.1136/hrt.2003.028092

See end of article for authors' affiliations

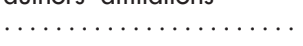

Correspondence to: Dr Brit Dybdahl,

Department of Oncology, Ulleval University Hospital, 0407 Oslo, Norway: brit.dybdahl@ulleval.no

Accepted 10 May 2004
Objectives: To test the hypothesis that heat shock protein ( $\mathrm{Hsp}) 70$ may be released into the circulation after acute myocardial infarction (AMI) by exploring the kinetics of $\mathrm{Hsp70}$ release and the relations between $\mathrm{Hsp70}$ and markers of inflammation and myocardial damage in AMI.

Design: Blood samples from 24 patients were prospectively collected through to the first day after AMI. Hsp70, interleukin (IL) 6, IL-8, and IL-10 in serum were measured by enzyme linked immunosorbent assay (ELISA).

Results: Median Hsp70 concentrations in AMI patients measured at arrival, six hours thereafter, and the following morning were 686,868 , and $607 \mathrm{pg} / \mathrm{ml}$, respectively. These concentrations were all significantly different from those of the control patients with angina with a median serum Hsp70 concentration of $306 \mathrm{pg} / \mathrm{ml}$. Peak Hsp70 correlated with creatine kinase (CK) MB $(r=0.62, \mathrm{p}<0.01)$ and cardiac troponin $\mathrm{T}(r=0.58, \mathrm{p}<0.01)$. Furthermore, serum Hsp70 correlated with IL-6 and IL-8 at six hours ( $r=0.60, \mathrm{p}<0.01$ and $r=0.59, \mathrm{p}<0.01$, respectively).

Conclusions: In this study, $\mathrm{Hsp} 70$ was rapidly released into the circulation after AMI. Circulating Hsp70 is suggested as a marker of myocardial damage. In addition, $\mathrm{Hsp} 70$ may have a role in the inflammatory response after AMI.
A therosclerosis is well recognised as a proliferative inflammatory disease. ${ }^{1}$ In addition to inflammation in the coronary plaque, there may be a local inflammatory response in the myocardium after acute myocardial infarction (AMI) as part of the healing and scar formation processes. ${ }^{2}$ Patients who have had an AMI are also often observed to have a significant increase in $\mathrm{C}$ reactive protein (CRP), as well as fever, indicating a systemic inflammatory response. In this setting, serum CRP concentration may add to the value of serum cardiac troponins and creatine kinase (CK) MB in predicting early and late mortality. ${ }^{3}$ In unstable coronary artery disease, the proinflammatory interleukin (IL) 6 has been shown to be a strong independent marker of increased mortality. ${ }^{4}$ It has been suggested that the myocardial damage may be related to the degree of inflammation. $^{5}$ The link between myocardial ischaemia-reperfusion and the systemic inflammatory response is not yet fully elucidated, which inspired us to perform this pilot study.

Heat shock proteins (Hsp) are abundant, soluble intracellular proteins. ${ }^{6}$ Some Hsp are constitutively expressed, whereas others are induced upon cell stress such as ischaemia. The inducible Hsp70 family member Hsp70 (also called Hsp72) is located in the cytosol and the nucleus of the cells. ${ }^{6}$ Hsp are molecular chaperones with a principal function in intracellular repair processes, associating with peptides and assisting protein folding and transport, and may associate with self peptides as well as with antigenic peptides. $^{7}$ After cell stress or death, Hsp peptide complexes may be presented on the cell surface or released to the surroundings, thereby activating cells of the adaptive immune system. ${ }^{67}$ Furthermore, extracellular Hsp has previously been suggested to activate innate immune mechanisms ${ }^{6-14}$ thus signalling cell stress and damage to the immune system. ${ }^{8}$ Several groups have shown that the inducible Hsp70 may activate cells through toll-like receptor (TLR) 2, TLR-4, and $\mathrm{CDI} 4{ }^{10-14}$ thereby mediating proinflammatory cytokine production through the myeloid differentiation factor 88-ILIR associated kinase-nuclear factor $\kappa \mathrm{B}$ signal transduction pathway. ${ }^{12} 13$
There is evidence for a protective role of Hsp, especially Hsp70, in atherosclerosis and myocardial ischaemia. ${ }^{15}$ Hsp70 may counteract important mechanisms of ischaemic injury including unfolding, misfolding, or pathological modification of critical proteins. ${ }^{16-18}$ Increased concentrations of Hsp72 have been detected in heart biopsies from patients with unstable as compared with stable angina, ${ }^{19}$ and we have previously detected Hsp70 in the circulation after coronary artery bypass grafting. ${ }^{14} 20$ Accordingly, our first hypothesis was that AMI leads to induction of Hsp70 in the heart and release into the circulation. Secondly, we hypothesised that circulating Hsp70 may correlate with the extent of myocardial damage in AMI and, lastly, that serum Hsp70 after AMI should be related to the systemic inflammatory response. Thus, our main purpose was to study the kinetics of Hsp70 release after AMI. Our second aim was relating serum Hsp70 concentration to well known serum markers of myocardial necrosis and inflammation after AMI.

\section{METHODS}

The present study conforms to the principles outlined in the Declaration of Helsinki.

\section{Patients and controls}

From September 2001 through August 2002, 28 patients were enrolled in this prospective study at Trondheim University ( $\mathrm{St}$ Olav) Hospital, Trondheim, Norway. The inclusion criteria were chest pain for more than 20 minutes (but less than 12 hours) and strong clinical suspicion of AMI with or without ECG changes. The diagnosis of AMI was secured by echocardiography and the typical rise and fall of the biochemical markers cardiac troponin $\mathrm{T}$ (cTnT) and CK-MB, in addition to the presence of ischaemic symptoms. The patients were enrolled at arrival in the emergency unit, and

Abbreviations: $\mathrm{AMI}$, acute myocardial infarction; $\mathrm{CK}$, creatine kinase; CRP, $C$ reactive protein; $\mathrm{CTnT}$, cardiac troponin T; ELISA, enzyme linked immunosorbent assay; $\mathrm{Hsp}$, heat shock protein; IL, interleukin; $\mathrm{PCl}$, percutaneous coronary intervention; TLR, toll-like receptor 


\begin{tabular}{ll}
$\begin{array}{l}\text { Table } 1 \\
\text { characteristics ( } \mathrm{n}=24)\end{array}$ \\
\hline Characteristic & Value \\
\hline Age (years) & $57.0(49.5,63.0)$ \\
Male/female & $19 / 5$ \\
Anterior Ml & 9 \\
Inferior Ml & 13 \\
Non-Q wave MI & 2 \\
Time from pain onset to hospital \\
admission (hours) & $3.0(1.0,4.4)$ \\
LVEF (\%) & $50(50,65)$ \\
Thrombolysis & 11 \\
Primary PCI & 12 \\
Rescue PCI & 1 \\
In-CCU stay (days) & $2.0(1.0,2.0)$ \\
In-hospital stay (days) & $7.0(6.0,8.0)$ \\
30 day mortality & 1 \\
\hline Data are median (first and third quartiles) or number of \\
patients. \\
CCU, coronary care unit; LVEF, left ventricular ejection \\
fraction; Ml, myocardial infarction; PCl, percutaneous \\
coronary intervention. \\
\hline
\end{tabular}

only at daytime. The intention was to enrol consecutive patients, as the nurses should notify the investigators when they arrived. We missed some putative patient inclusions because of busy times for the nurses in the emergency unit. All of the patients were transferred to the coronary care unit for further treatment and observation. Patients were enrolled regardless of whether they were undergoing primary percutaneous coronary intervention (PCI), thrombolysis, or conservative treatment. They were $<75$ years old and had no signs of infection or acute pulmonary disease at enrolment. Patients with ventricular fibrillation or asystole, having been resuscitated before admission, and unconscious patients were not included. Patients turning out not to have AMI were excluded from the study. Informed written consent was obtained from each patient and the regional ethics committee approved the study.

Table 1 lists patient characteristics. Of the 28 patients enrolled, four were excluded: one because of failure in the blood test procedure and three because of wrong diagnosis. The remaining 24 patients had AMI as shown by the increase in CTnT (fig 1) and CK-MB (fig 2). Of the 11 patients treated with thrombolytic agents, seven received reteplase and four received streptokinase. Another 11 patients were transported directly from the emergency unit to the laboratory for primary PCI, whereas one patient had primary PCI after the

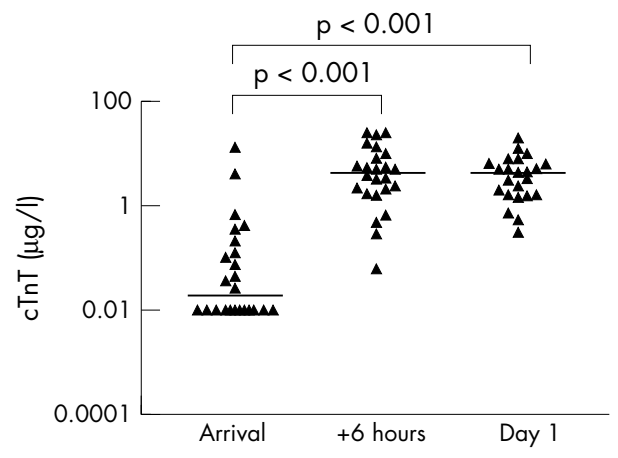

Figure 1 Serum cardiac troponin $\mathrm{T}(\mathrm{cTnT}, \mathrm{n}=24)$ after acute myocardial infarction (AMI), individual and median concentrations (horizontal bars). The median concentrations at the three time points were $0.02,4.32$, and $4.33 \mu \mathrm{g} / \mathrm{ml}$. cTnT concentration increased significantly from arrival to six hours later and from arrival to the following day. $\log _{10}$ scale is used on the vertical axis. One blood test from the third sampling was lost. first bolus of reteplase. All of the patients with primary ECG changes had signs of reperfusion within 90 minutes, except for one patient who had rescue PCI after streptokinase treatment. The main criteria for primary PCI were short time from pain onset to hospital admission and ECG changes indicating AMI. Two patients had neither thrombolysis nor PCI, due to initial uncertainty of diagnosis or contraindications. One of these, who also had insulin dependent diabetes mellitus with complications and acute bacterial pneumonia, after two days died of brain infarction. Another patient with verified anterior AMI, treated with reteplase before admission to the hospital, had a 31 day in-hospital stay complicated with heart failure and pneumonia. The rest of the patients had uncomplicated myocardial infarctions.

Twenty age and sex matched patients with angina constituted the control group. They were recruited at the St Elisabeth Heart Centre, Trondheim, Norway, as part of another study. ${ }^{20}$ These patients were scheduled for elective coronary artery bypass grafting and none had an AMI during the preceding 14 days. Preoperative blood samples served as controls for the present study.

\section{Blood sampling}

Blood was sampled through venepuncture immediately after admission to the emergency unit, after six hours, on the following morning (12-15 hours after test 2), and thereafter as needed. Routine tests measuring CTnT, CK-MB, CRP, and haematological parameters were done by the department of clinical chemistry, Trondheim University Hospital. Through the first day, an extra blood sample was taken concomitantly with the routine tests. This sample was centrifuged after 30 minutes of coagulation and serum was aliquoted and frozen in several vials at $-80^{\circ} \mathrm{C}$ until analysed for Hsp70, IL-6, IL-8, and IL-10.

\section{Serum analyses}

Serum Hsp70 was measured with a StressXpress Hsp70 enzyme linked immunosorbent assay (ELISA) kit (Stressgen Biotechnologies Corp, Victoria, British Columbia, Canada) with a sensitivity of $200 \mathrm{pg} / \mathrm{ml}$ and interassay and intra-assay coefficients of variation $<10 \%$. IL- 6 and IL- 8 were measured with Quantikine Human Immunoassays (R\&D Systems Inc, Minneapolis, Minnesota, USA) with sensitivities of $0.70 \mathrm{pg} /$ $\mathrm{ml}$ and $10 \mathrm{pg} / \mathrm{ml}$, respectively. Serum IL-10 was analysed with Biosource IL-10 EASIA Kit (Biosource Europe SA, Nivelles, Belgium) with a sensitivity of $1 \mathrm{pg} / \mathrm{ml}$. cTnT and CK-MB were measured by means of electrochemiluminescence immunoassay technology on an Elecsys 2010 Analyser

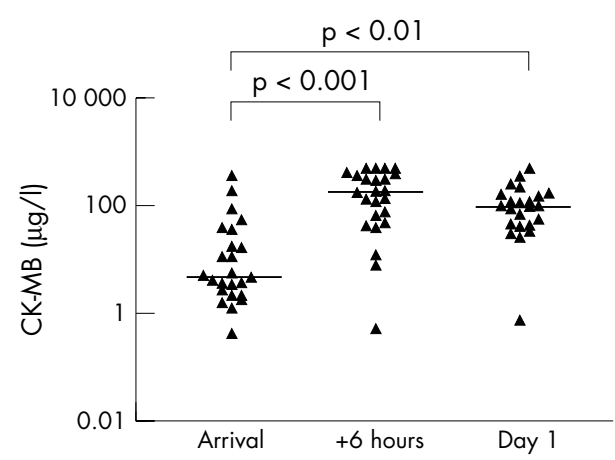

Figure 2 Serum creatine kinase $M B(C K-M B)$ in patients with $A M I$ $(\mathrm{n}=24)$. Individual concentrations and medians are shown. Median serum concentrations at the three time points were 4.7, 178.3, and $97.3 \mu \mathrm{g} / \mathrm{ml}$. The increases in CK-MB from hospital admission to both six hours later and the following day were significant. $\log _{10}$ scale is used on the vertical axis. One sample from day 1 was lost. 


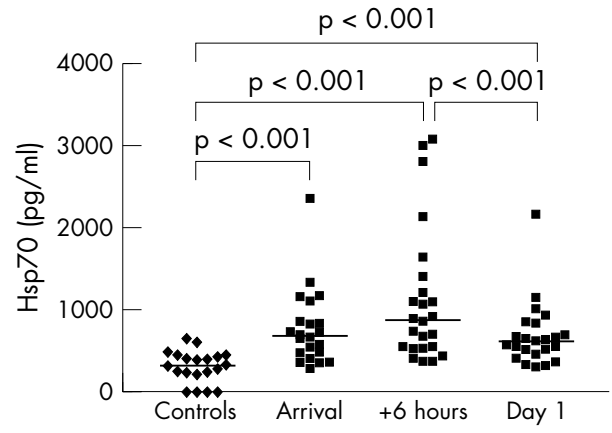

Figure 3 Serum heat shock protein ( $\mathrm{Hsp}) 70$ in controls (patients with angina pectoris, $n=20)$ and the first day after $A M I(n=24)$. Individual and median concentrations (horizontal bars) are shown. In controls, median (first and third quartile) serum Hsp70 was 306 (207, 423) $\mathrm{pg} / \mathrm{ml}$. Median (first and third quartiles) serum Hsp70

concentrations in patients with $\mathrm{AMl}$ at the consecutive time points were $686(466,1103), 868(525,1350)$ and $607(445,823) \mathrm{pg} / \mathrm{ml}$. Two $\mathrm{Hsp} 70$ concentrations from the arrival are not plotted because of analysis problems. One blood sample obtained the day after AMI was lost.

(Roche) with detection ranges of $0.01-25.00 \mu \mathrm{g} / \mathrm{l}$ and $0.10-$ $500 \mu \mathrm{g} / \mathrm{l}$, respectively. Cut off values in the diagnosis of AMI were determined to be $>0.10 \mu \mathrm{g} / \mathrm{l}$ for $\mathrm{CTnT}$ and $>10.0 \mu \mathrm{g} / \mathrm{l}$ for CK-MB. Routine hospital analyses were used for quantification of CRP (detection limit $5 \mathrm{mg} / \mathrm{l}$ ), leucocyte counts, high density lipoprotein cholesterol, total cholesterol, and triglycerides.

\section{Statistical analyses}

Owing to the non-Gaussian distribution of most data, we used non-parametric tests and median values with quartiles. We used the Mann-Whitney test to compare cases with controls and to compare subgroups. We used the Wilcoxon signed ranks test to compare two related samples. Comparisons within groups over time were made by means of the Friedman test and Dunn's multiple comparison test. Differences were considered significant $\mathrm{p}<0.05$. For correlation analyses, we used Spearman's rho.

\section{RESULTS}

\section{Hsp70 and myocardial damage}

Serum Hsp70 in patients with AMI were significantly higher than in the control group at all time points (fig 3). Hsp70 concentrations in patients with AMI peaked six hours after their arrival (median $868 \mathrm{pg} / \mathrm{ml}$ ). In comparison, the control group had a median serum Hsp70 concentration of $306 \mathrm{pg} /$ ml. Hsp70 decreased significantly in the patients with AMI from the day of arrival to the following morning, in contrast to cTnT (fig 1) and CK-MB (fig 2). Median serum cTnT was at maximum at 8 am the following day $(4.33 \mu \mathrm{g} / \mathrm{l})$ in patients with AMI. Moreover, their peak median CK-MB concentration was $178.3 \mu \mathrm{g} / \mathrm{l}$ six hours after arrival at the hospital. Control patients had a median cTnT $<0.01 \mu \mathrm{g} / \mathrm{l}$ and median CK-MB $1.4 \mu \mathrm{g} / \mathrm{l}$, both significantly lower $(\mathrm{p}<0.01)$ than the corresponding concentrations in patients with AMI. Median time from pain onset to hospital admission in our patients was 1.8 hours in patients undergoing primary PCI versus 4.0 hours in patients not treated with primary PCI ( $p<0.05$ ).

The peak Hsp70 concentration correlated with time from pain onset to hospital admission $(r=0.54, \mathrm{p}<0.01)$. Furthermore, peak Hsp70 in serum correlated with the peak concentrations of the markers of myocardial necrosis CK-MB $(r=0.62, \mathrm{p}<0.01)$ and cTnT $(r=0.58, \mathrm{p}<0.01)($ fig $4 \mathrm{~A}$, B) measured at the same time points. Hsp70 both at arrival and at six hours correlated with CTnT measured on day 1
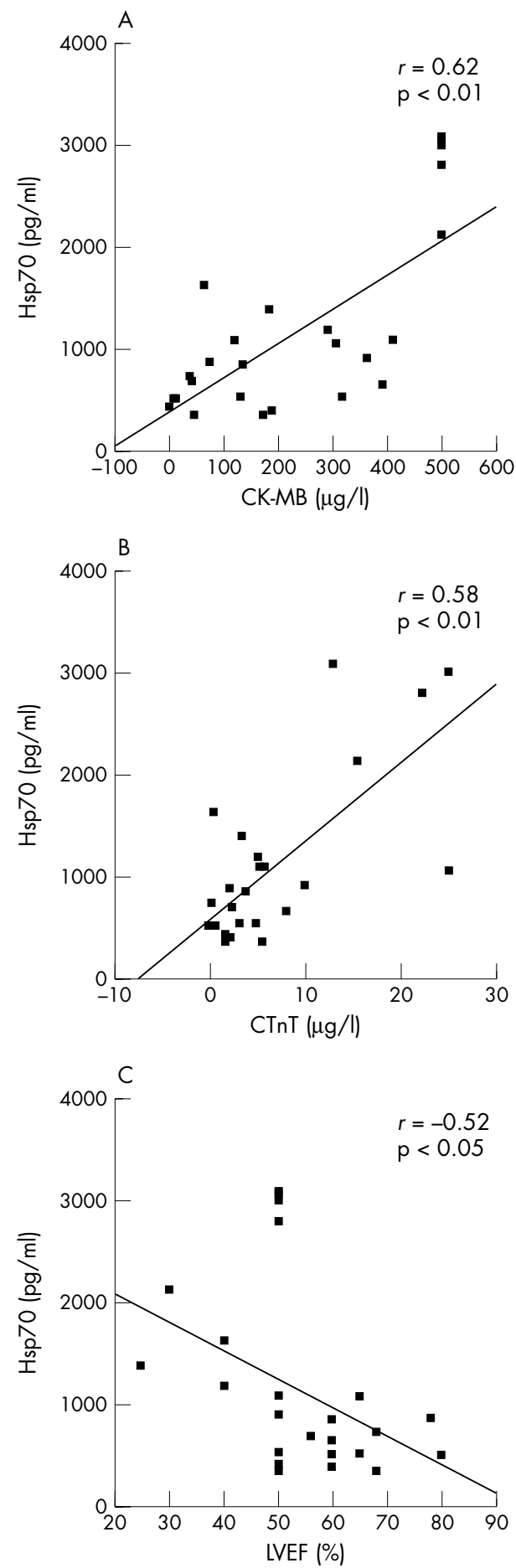

Figure 4 Correlations shown by means of scatter plots with fit lines for peak $\mathrm{Hsp70}$ versus (A) peak CK-MB, (B) peak cTnT, and (C) left ventricular ejection fraction (LVEF).

( $r=0.51, \mathrm{p}<0.05$ and $r=0.67, \mathrm{p}<0.01$, respectively), illustrating the more rapid release of Hsp70. Interestingly, left ventricular ejection fraction correlated negatively with peak Hsp70 concentration $(r=-0.52, \mathrm{p}<0.05)$ (fig 4C).

Studying each individual patient carefully, we discovered that there were none that had low serum cTnT combined with high Hsp70 concentrations. Patients with AMI and high Hsp70 concentrations at arrival usually retained a higher serum Hsp70 concentration during the first day compared 
Table 2 Laboratory data $(n=24)$

\begin{tabular}{lll}
\hline Parameter & At arrival & On day 1 \\
\hline Total cholesterol $(\mathrm{mmol} / \mathrm{I})$ & & $5.9(4.7,6.7)$ \\
$\mathrm{HDL}$ cholesterol $(\mathrm{mmol} / \mathrm{l})$ & $1.0(0.91,1.3)$ \\
Triglycerides $(\mathrm{mmol} / \mathrm{I})$ & $1.6(1.0,2.6)$ \\
$\mathrm{CRP}(\mathrm{mg} / \mathrm{l})$ & $<5.0(<5.0-6.0)$ & $10.0(6.0,42.3)$ \\
Leucocytes $\left(\times 10^{9} / \mathrm{l}\right)$ & $10.6(7.7-12.0)$ & $9.2(7.8,12.1)$ \\
\hline Data are median (first, third quartiles). & \\
CRP, C reactive protein; HDL, high density lipoprotein.
\end{tabular}

with patients with lower initial concentrations. One of our patients, a 63 year old woman who had a large myocardial infarction, had Hsp70 concentrations of 2351, 2120, and $1001 \mathrm{pg} / \mathrm{ml}$, respectively, measured at admission, six hours later, and the morning after. A second example is a 51 year old man with an occluded right coronary artery, experiencing his first myocardial infarction, with corresponding serum Hsp70 concentrations of $81 \mathrm{l}, 1090$, and $540 \mathrm{pg} / \mathrm{ml}$, respectively.

\section{Systemic inflammation}

Control patients had CRP $<5 \mathrm{mg} / \mathrm{l}$, median IL-6 $2.4 \mathrm{pg} / \mathrm{ml}$, and median IL-8 $13.2 \mathrm{pg} / \mathrm{ml}$. Table 2 shows supplementary laboratory values for the patients with AMI. There was a significant increase in CRP from admission to the following morning $(p<0.01)$. Figures 5 and 6 show the results of serum IL-6 and IL-8 measurements, respectively. The IL-6 median concentration peaked at $14.1 \mathrm{pg} / \mathrm{ml}$ the day after arrival. Serum IL-6 concentrations in controls were significantly $(\mathrm{p}<0.01)$ lower than in patients with AMI at all time points. For patients with AMI, there was a significant increase in IL-6 from the day of arrival to the day after, thereby having kinetics different from Hsp70. In contrast, the IL-8 concentration was quite low and did not increase during the first day after AMI. Median serum IL-8 was 15.3 pg/ml measured the morning after the insult.

We detected a strong correlation between the proinflammatory IL-6 and Hsp70 measured at six hours after arrival at the hospital $(r=0.60, \mathrm{p}<0.01)$. There was still a correlation between IL-6 and Hsp70 the following day, though it was weaker $(r=0.44, \mathrm{p}<0.05)$. At six hours, IL-6 also correlated with CK-MB $(r=0.58, \mathrm{p}<0.01)$ and CTnT $(r=0.48, \mathrm{p}<0.05)$, indicating a possible relation between myocardial damage and systemic inflammation. The chemokine IL-8 correlated with Hsp70 at six hours after hospital admission $(r=0.59, \mathrm{p}<0.01)$ but not the day after. IL-8 correlated with CK-MB six hours after hospital admission $(r=0.45, \mathrm{p}<0.05)$ but no correlation with cTnT was detected. In addition, CRP measured on day 1 after the AMI correlated with the peak Hsp70 $(r=0.56, \mathrm{p}<0.01)$.

Four patients had detectable concentrations of the antiinflammatory IL-10 at arrival at the hospital (range 6.6$16.1 \mathrm{pg} / \mathrm{ml}$ ). IL-10 was not further statistically analysed because of the small number of patients with detectable concentrations of this cytokine.

\section{DISCUSSION}

The main findings in the present study were increased serum Hsp70 concentrations in patients with AMI as compared with patients with angina pectoris. Furthermore, peak serum Hsp70 concentrations correlated both with markers of myocardial necrosis and with proinflammatory markers. Lastly, in patients with AMI serum Hsp70 concentration increased and declined more rapidly than the well known markers of myocardial necrosis, cTnT and CK-MB. We are not aware of previously published studies on circulating Hsp70 after AMI

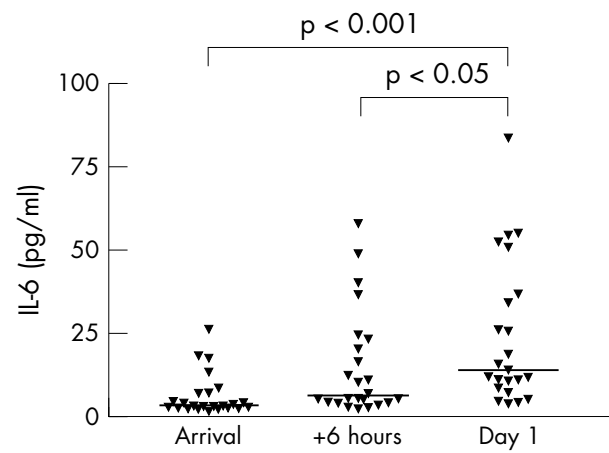

Figure 5 Serum interleukin (IL) 6 in patients after AMI $(n=24)$. Individual concentrations and medians (horizontal bars) are shown. Median (first and third quartiles) concentrations at the three time points were $3.4(2.6,7.1), 6.6(4.3,22.7)$, and $14.1(8.5,37.0) \mathrm{pg} / \mathrm{ml}$. One blood sample from the day after AMI was lost.

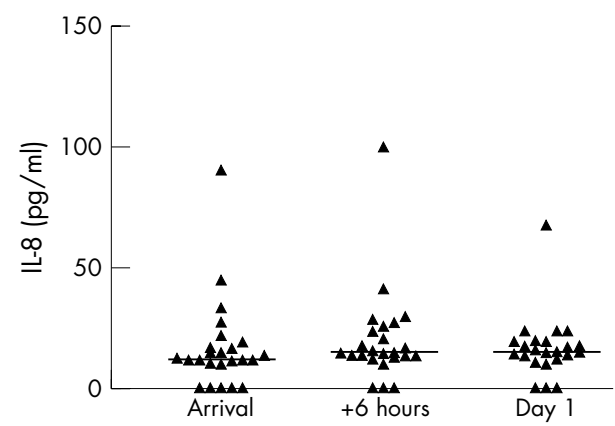

Figure 6 Serum IL-8 after AMI ( $n=24)$. Individual concentrations and medians (horizontal bars) are shown. Median (first and third quartiles) concentrations at the three time points were $12.2(10.3,18.4), 14.8$ $(13.0,25.6)$, and $15.3(12.1,19.5) \mathrm{pg} / \mathrm{ml}$. One sample from the day after AMI was lost. There were no significant differences between the measurements at the three time points.

\section{Sources of Hsp70}

The present study did not explore the sources of circulating Hsp70 after AMI. Previous studies have shown that Hsp70 may be induced in myocardial cells after stress, ${ }^{18}$ in unstable angina pectoris, ${ }^{19}$ after cardioplegic arrest, ${ }^{21}$ in stunned myocardium, ${ }^{22}$ and after coronary artery ligation. ${ }^{23}$ One study suggested that Hsp70 is abundantly expressed in small blood vessels between ventricular cardiomyocytes but not in the cardiomyocytes themselves. ${ }^{24}$ Furthermore, Hsp70 has been detected in leucocytes, ${ }^{25}$ atherosclerotic plaques, smooth muscle cells, and macrophages, as well as in relation to necrosis and lipid accumulation. ${ }^{26}$ Recently, expression of the Hsp70 family genes HspAl2A and HspAl2B has been detected in murine aortic atherosclerotic lesions. ${ }^{27}$ Lastly, heat shock transcription factor 1 has been suggested to be expressed and activated in atherosclerotic lesions. ${ }^{28}$ The sources of circulating Hsp70 after AMI, whether they are myocardial cells, atherosclerotic plaques, or extracardiac, have not been determined. It is also unknown how much of the Hsp70 induced intracellularly (for example, in the heart) is actually released into the systemic circulation. We suggest, however, that the Hsp70 concentration in serum after AMI most probably mirrors the Hsp70 concentration in the heart.

\section{Hsp70 and myocardial necrosis}

All of our patients had myocardial necrosis as shown by the increase in cTnT and CK-MB, as well as by typical echocardiographic findings. CTnT and CK-MB are well known markers of myocardial necrosis. ${ }^{29}{ }^{30}$ As a group, our patients 
with AMI had moderate peak CTnT concentrations, although with substantial individual differences. We clearly detected a correlation between markers of myocardial damage and serum Hsp70 in our patients. This may indicate that the Hsp70 concentration is related to the size of the infarction and therefore to the prognosis, even though the relation between the size of the infarction and markers of necrosis is less obvious after a revascularisation procedure. ${ }^{31}$ On the other hand, the observation that patients with higher serum Hsp70 concentrations had lower left ventricular ejection fractions the first day after AMI supports the idea that the Hsp70 concentration is related to the size of the infarction. Thus, we suggest that circulating Hsp70 after AMI may be a marker of myocardial damage.

\section{Hsp70 kinetics}

An important difference between the established markers of myocardial necrosis, cTnT and CK-MB, and Hsp70 is their kinetics: Hsp70 appears to be more rapidly released and cleared from the circulation. The biological half life of Hsp70 has been reported to be about 18 hours. ${ }^{32}$ In AMI, cTnT is still high several days after the primary insult. ${ }^{33}$ Measuring Hsp70 may be of value in detecting reinfarction during the first few days after the primary AMI.

\section{Systemic inflammatory response in AMI}

An inflammatory response appeared after AMI in the study patients. We detected an increase in IL- 6 and CRP during the first day, in accordance with previous studies. ${ }^{33}{ }^{34}$ We observed that IL-8, important in chemotaxis and angiogenesis after reperfusion in $\mathrm{AMI}^{3}{ }^{3}$ did not change significantly during the first day after AMI. One patient (who died on day 2), however, had high IL-8 concentrations. Other studies have had conflicting results on the role of IL-8 in acute coronary syndromes. ${ }^{35} 36$

Furthermore, as shown in previous studies, increased serum concentrations of the anti-inflammatory IL-10 are associated with a more favourable prognosis for patients with acute coronary syndromes and increased $\mathrm{CRP},{ }^{37}$ and patients with unstable angina pectoris may have lower concentrations of IL-10 than patients with chronic stable angina. ${ }^{38} \mathrm{We}$ detected IL-10 in only four of our 24 patients. Thus, for statistical reasons, we should not draw conclusions about the relation between Hsp70 and IL-10 from this investigation.

\section{Hsp70 and the immune system}

The median serum Hsp70 concentration after AMI in our patients was not very high. Whether this amount of systemic Hsp70 is enough to stimulate circulating cells of the immune system remains to be elucidated. In vitro, concentrations of Hsp70 up to $0.1-10 \mu \mathrm{g} / \mathrm{ml}$ have been used to stimulate monocytes. Nevertheless, our patients' results may support a relation between $\mathrm{Hsp70}$ and a systemic inflammatory response. Besides the possibility of a systemic Hsp70 effect, Hsp70 may have an important role locally in the heart, not only as a chaperone but also as a signalling molecule.

Expression of TLR-4 is reported in the human myocardium. $^{39}$ As a putative TLR ligand, ${ }^{10-14}$ Hsp70 has been suggested to activate innate immunity in injured myocardium, coronary arteries, and monocytes in vivo. However, the mechanism by which Hsp70 may activate innate immunity is unknown. Results from a recent study show that recombinant preparations of human Hsp70 may be contaminated by endotoxin, a known TLR-4 ligand. ${ }^{40}$ An alternative interpretation of existing data may be that Hsp70 has an endotoxin binding function, delivering endotoxin to receptor complexes including TLR-4 on antigen presenting cells. ${ }^{8}$
Importantly, Hsp70 may activate adaptive immunity as well through the CD91 receptor on antigen presenting cells, ${ }^{6}$ thereby inducing Th2-type $\mathrm{CD} 4^{+} \mathrm{T}$ cells, synthesising IL-10 among others. ${ }^{41}$ As such, Hsp70 may be part of an immunoregulatory response that has the potential to control proinflammatory responses. ${ }^{41}$

\section{Study limitations}

It remains to be clarified whether Hsp70 is a valid clinical marker for cardiac damage. The sample size in the study is too small to allow any definite conclusions in this regard. Furthermore, our patients had small myocardial infarctions. This appears to be a consequence of early and intense treatment. With larger infarctions, we would expect to detect even larger differences in serum Hsp70 than we did between patients with angina and patients with AMI. Nevertheless, the main findings of this pilot study may generate hypotheses and support further investigation.

\section{Conclusions}

To summarise, Hsp70 was rapidly released and cleared from the circulation after AMI and may be suggested as an additional marker of myocardial damage. Besides its known function in intracellular repair processes, Hsp70 may activate the immune system, thus having a role in both local and systemic inflammatory responses after AMI.

\section{ACKNOWLEDGEMENTS}

We appreciate the support of the staff at the emergency and coronary care units at Trondheim University Hospital during this study.

\section{Authors' affiliations}

B Dybdahl* T Espevik, A Sundan, Institute of Cancer Research and

Molecular Medicine, Faculty of Medicine, Norwegian University of Science and Technology, Trondheim, Norway

P Kierulf, The R \& D Group, Department of Clinical Chemistry, Ulleval University Hospital, Oslo, Norway

S A Slørdahl, Department of Circulation and Medical Imaging, Faculty of Medicine, Norwegian University of Science and Technology

A Waage, Department of Medicine, Section for Haematology,

Trondheim University Hospital, Trondheim, Norway

*Also the R \& D Group, Department of Clinical Chemistry, Ulleval University Hospital

There is no conflict of interest.

\section{REFERENCES}

1 Ross R. Atherosclerosis: an inflammatory disease. N Engl J Med 1999;340:115-26.

2 Frangogiannis NG, Smith CW, Entman ML. The inflammatory response in myocardial infarction. Cardiovasc Res 2002;53:31-47.

3 Ridker PM. Clinical application of C-reactive protein for cardiovascular disease detection and prevention. Circulation 2003;107:363-9.

4 Lindmark E, Diderholm E, Wallentin L, et al. Relationship between interleukin 6 and mortality in patients with unstable coronary artery disease: effects of an early invasive or non-invasive strategy. JAMA 2001;286:2107-13.

5 Oldgren J, Wallentin L, Grip L, et al. Myocardial damage, inflammation and thrombin inhibition in unstable coronary artery disease. Eur Heart J 2003;24:86-93.

6 Srivastava P. Roles of heat-shock proteins in innate and adaptive immunity. Nature Rev Immunol 2002;2:185-94.

7 Li Z, Menoret A, Srivastava P. Roles of heat-shock proteins in antigen presentation and cross-presentation. Curr Opin Immunol 2002;14:45-51.

8 Wallin RPA, Lundqvist A, Moré SH, et al. Heat-shock proteins as activators of the innate immune system. Trends Immunol 2002;23:130-5.

9 Bethke K, Staib F, Distler M, et al. Different efficiency of heat shock proteins (HSP) to activate human monocytes and dendritic cells: superiority of HSP60. $\mathrm{J}$ Immunol 2002;169:6141-8.

10 Akira S. Mammalian toll-like receptors. Curr Opin Immunol 2003;15:5-11.

11 Asea A, Kraeft S-K, Kurt-Jones EA, et al. HSP70 stimulates cytokine production through a CD14-dependant pathway, demonstrating its dual role as a chaperone and cytokine. Nat Med 2000;6:435-42.

12 Asea A, Rehli M, Kabingu E, et al. Novel signal transduction pathway utilized by extracellular HSP7O: role of toll-like receptor (TLR)2 and TLR4. J Biol Chem 2002;277: 15028-34. 
13 Vabulas RM, Ahmad-Nejad P, Ghose S, et al. HSP70 as endogenous stimulus of the toll/interleukin-1 receptor signal pathway. J Biol Chem 2002;277:15107-12.

14 Dybdahl B, Wahba A, Lien E, et al. Inflammatory response after open heart surgery: release of heat-shock protein 70 and signaling through toll-like receptor-4. Circulation 2002; 105:685-90.

15 Xu Q. Role of heat shock proteins in atherosclerosis. Arterioscler Thromb Vasc Biol 2002;22:1547-59.

16 Williams RS, Benjamin IJ. Protective responses in the ischemic myocardium. J Clin Invest 2000;106:813-8.

17 Latchman DS. Heat shock proteins and cardiac protection. Cardiovasc Res 2001;51:637-46.

18 Snoeckx LH, Cornelussen RN, van Nieuwenhoven FA, et al. Heat shock proteins and cardiovascular pathophysiology. Physiol Rev 2001;81:1461-97.

19 Valen G. Hansson GK, Dumitrescu A, et al. Unstable angina activates myocardial heat shock protein 72 , endothelial nitric oxide synthase, and transcription factors NF- $\mathrm{KB}$ and AP-1. Cardiovasc Res 2000;47:49-56.

20 Dybdahl B, Wahba A, Haaverstad R, et al. On-pump versus off-pump coronary artery bypass grafting: more heat-shock protein 70 is released after on-pump surgery. Eur J Cardiothorac Surg 2004;25:985-92.

21 Schmitt JP, Schunkert H, Birnbaum DE, et al. Kinetics of heat shock protein 70 synthesis in the human heart after cold cardioplegic arrest. Eur J Cardiothorac Surg 2002;22:415-20.

22 Lüss H, Schäfers $M$, Neumann J, et al. Biochemical mechanisms of hibernation and stunning in the human heart. Cardiovas Res 2002;56:411-21.

23 Tanonaka K, Yoshida H, Toga W, et al. Myocardial heat shock proteins during the development of heart failure. Biochem Biophys Res Commun 2001:283:520-5.

24 Leger JP, Smith FM, Currie RW. Confocal microscopic localization of constitutive and heat shock-induced proteins HSP70 and HSP27 in the rat heart. Circulation 2000;102:1703-9.

25 Fehrenbach E, Niess AM, Schlotz E, et al. Transcriptional and translational regulation of heat shock proteins in leukocytes of endurance runners. J Appl Physiol 2000;89:704-10.

26 Berberian PA, Myers W, Tytell M, et al. Immunohistochemical localization of heat shock protein-70 in normal-appearing and atherosclerotic specimens of human arteries. Am J Pathol 1990;136:71-80.

27 Han Z, Truong QA, Park S, et al. Two Hsp70 family members expressed in atherosclerotic lesions. Proc Natl Acad Sci USA 2003;100:1256-61.

28 Metzler B, Abia R, Ahmad M, et al. Activation of heat shock transcription factor 1 in atherosclerosis. Am J Pathol 2003;162:1669-76.
29 Alpert JS, Thygesen K. Myocardial infarction redefined: a consensus document of The Joint European Society of Cardiology/American College of Cardiology Committee for the Redefinition of Myocardial Infarction. Eur Heart J 2000;21:1502-13.

30 Collinson PO Stubbs PJ, Kessler AC. Multicentre evaluation of routine immunoassay of troponin T study. Multicentre evaluation of the diagnostic value of cardiac troponin T, CK-MB mass, and myoglobin for assessing patients with suspected acute coronary syndromes in routine clinical practice. Heart 2003:89:280-6.

31 Licka M, Zimmermann R, Zehelein J, et al. Troponin T concentrations 72 hours after myocardial infarction as a serological estimate of infarct size. Heart 2002;87:520-4.

32 Gerner C, Vejda S, Gelbmann D, et al. Concomitant determination of absolute values of cellular protein amounts, synthesis rates, and turnover rates by quantitative proteome profiling. Mol Cell Proteomics 2002;1:528-37.

33 Kotajima N, Kimura T, Kanda T, et al. Reciprocal increase of circulating interleukin-10 and interleukin- 6 in patients with acute myocardial infarction. Heart 2001;86:704-5.

34 Blake GJ, Ridker PM. Inflammatory bio-markers and cardiovascular risk prediction. J Intern Med 2002;252:283-4.

35 Anguera I, Miranda-Guardiola F, Bosch X, et al. Elevation of serum levels of the anti-inflammatory cytokine interleukin-10 and decreased risk of coronary events in patients with unstable angina. Am Heart J 2002;144:811-7.

36 Manten A, de Winter RJ, Minnema MC, et al. Procoagulant and proinflammatory activity in acute coronary syndromes. Cardiovasc Res 1998;40:389-95.

37 Heeschen C, Dimmeler S, Hamm CW, CAPTURE Study Investigators. Serum level of the antiinflammatory cytokine interleukin-10 is an important prognostic determinant in patients with acute coronary syndromes. Circulation 2003;107:2109-14.

38 Smith DA, Irving SD, Sheldon J, et al. Serum levels of the anti-inflammatory cytokine interleukin-10 are decreased in patients with unstable angina. Circulation $2001 ; 104: 746-9$

39 Frantz S, Kobzik L, Kim Y-D, et al. Toll4 (TLR4) expression in cardiac myocytes in normal and failing myocardium. J Clin Invest 1999;104:271-80.

40 Gao B, Tsan M-F. Endotoxin contamination in recombinant human heat shock protein $70(\mathrm{Hsp} 70)$ preparation is responsible for the induction of tumor necrosis factor $\alpha$ release by murine macrophages. J Biol Chem 2003;278:174-9.

41 Pockley AG. Heat shock proteins as regulators of the immune response. Lancet 2003;362:469-76.

\section{IMAGES IN CARDIOLOGY}

\section{Aortoenteric fistula as shown by multidetector computed tomography}

A

n 80 year old man with a history of abdominal aortic aneurysm, repaired

10 years previously, presented to the emergency room with a four hour history of severe epigastric pain. Examination demonstrated a distended, tender, but non-rigid abdomen. ECG was unremarkable. Shortly after arrival the patient suffered a sudden onset of massive haematemesis requiring replacement of large volumes of intravenous colloid and blood. Following successful resuscitation urgent endoscopy was undertaken, but failed to demonstrate a bleeding point because of large amounts of fresh blood in the stomach. Abdominal multidetector computed tomography (CT) (Siemens Forchheim, Somatom plus 4) was then performed. Axial images of the abdomen (panel A), at a level just inferior to the renal arteries, showed intravenous contrast medium in a slightly aneurysmal abdominal aorta (black solid arrow). Intravenous contrast medium is also seen outlining the inner wall of the third part of the duodenum (white arrow). An aortoenteric fistula is clearly identified between the two structures (black dashed arrow). Early renal cortical contrast enhancement is seen in the left
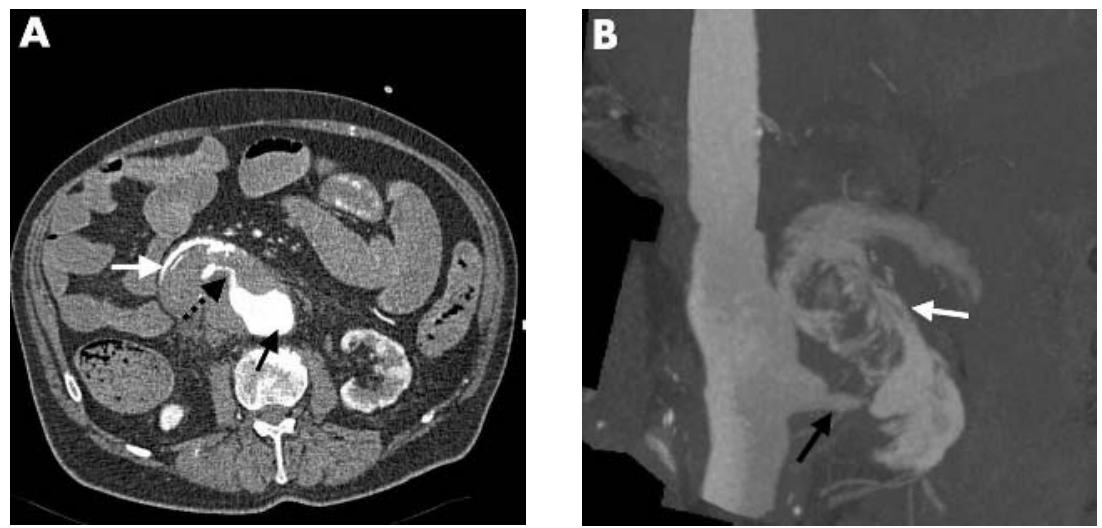

projection reconstruction (panel B), the aortoenteric fistula is once again demonstrated (black arrow) connecting the abdominal aorta to the third part of duodenum. The latter is outlined by intravenous contrast medium (white arrow).

Immediately following CT the patient was sent to the operating room, but rapidly deteriorated during transit and further attempts to resuscitate were unsuccessful.

I Kayani

A M Groves

R Syed

kidney demonstrating preservation of blood

mail.com 